2012

\title{
Sustainability of solid brick walls with retrofitted external hemp-lime insulation
}

\author{
Griffiths, R
}

http://hdl.handle.net/10026.1/9277

10.1108/02630801211256661

Structural Survey

Emerald

All content in PEARL is protected by copyright law. Author manuscripts are made available in accordance with publisher policies. Please cite only the published version using the details provided on the item record or document. In the absence of an open licence (e.g. Creative Commons), permissions for further reuse of content should be sought from the publisher or author. 


\title{
Sustainability of solid brick walls with retrofitted external hemp- lime insulation.
}

\section{Richard Griffiths and Steve Goodhew Plymouth University}

\begin{abstract}
Purpose

Dwellings constructed before 1920 often had solid brick walls with poor thermal performance. Today there is a drive to reduce both energy demand and carbon dioxide production. This paper will demonstrate that mixtures of chopped hemp straw with lime based binders added to the external surface of brick walls can substantially reduce the air to air thermal transmittance, or U-value $\mathrm{W} / \mathrm{m}^{2} \mathrm{~K}$, and that these mixtures provide a sustainable remedial treatment for solid brick walls. The aim is to achieve wall U-values as good as, or better than, the current UK Building Regulations design value of $0.30 \mathrm{~W} / \mathrm{m}^{2} \mathrm{~K}$.
\end{abstract}

\section{Methodology}

Several Microsoft Excel spread sheets have been constructed to determine the steady state and transient thermal properties of various brick walls. These spread sheets are validated by comparing their output with the published thermal data to be found in the CIBSE Design Guide. The sustainable aspects of a number of different externally hemp-lime insulated Victorian brick walls are described and discussed.

\section{Findings}

The U-values and the transient thermal properties of solid brick walls with thickness $110 \mathrm{~mm}, 220 \mathrm{~mm}$ and $340 \mathrm{~mm}$ are presented. The transient properties include the admittance, decrement factor and lag time. These walls are then considered with various added external layers of hemp-lime ranging in thickness from $50 \mathrm{~mm}$ to $300 \mathrm{~mm}$. Some solid brick walls have an added air cavity, created with studding and plywood sheathing, before the layer of hemp-lime. Walls with external tile hanging for sites with high exposure to driving rain are also discussed.

\section{Originality}


This work demonstrate the advantages of the energy saving and carbon dioxide sequestration achieved by adding $200 \mathrm{~mm}$ of a hemp-lime binder insulation to the exterior of Victorian brick walls of terraced dwellings.

Words: 285

Key words: brick walls, hemp-lime, thermal properties, energy, carbon dioxide.

Paper type: Research paper

\section{Introduction}

In temperate climates earth fired bricks have been used to construct terraced dwellings for many centuries. These terraces can be found in Europe and North America, for example in Belfast, Loughborough, Philadelphia and Toronto. Many of these solid brick walled dwellings are difficult to heat, HSB (2011) and HSB (2008), and the thermal performance could be improved by the addition of thermal insulation, thereby reducing both the demand for energy and production of carbon dioxide. The search for possible remedial strategies was discussed by Pett (2004).

The original builders were unconcerned about fuel efficiency, the production of carbon dioxide to the atmosphere or the embodied energy of materials. Today there is a need to minimise the use of energy and to decrease the production of carbon dioxide $\left(\mathrm{CO}_{2}\right)$. To this end sustainable building materials are sought, materials that will provide a thermally efficient wall, floor, or roof; materials that will not require large amounts of energy in the building construction, modification in use, or in the deconstruction processes. This paper will demonstrate that mixtures of chopped hemp straw with lime based binders added to the external surface of brick walls can substantially reduce the air to air thermal transmittance, or $\mathrm{U}$-value $\mathrm{W} / \mathrm{m}^{2} \mathrm{~K}$, and that these mixtures provide a sustainable remedial treatment for solid brick walls.

Hemp-lime, Bevan and Woolley (2008), is a mixture of hemp stalks, sometimes called shiv, with a lime-based binder and water. This mixture can be fabricated into blocks, and trowelled or sprayed onto a surface. Two important advantages of hemp-lime can be identified. (1) Using hemp-lime, rather than an oil-based insulation material, utilises a material with a lower embodied energy. (2) The 
utilisation of hemp shiv with lime based binders produces a unique building material with the advantage that while growing the hemp plant removes $\mathrm{CO}_{2}$ from the atmosphere. The lower embodied energy is debatable, but it is agreed that the sequestration of $\mathrm{CO}_{2}$ by growing hemp is significant. Hemp-lime can be fashioned into blocks to replicate thermal concrete blocks, Lime Technology (2009a), and structural blocks, Lime Technology (2009b). The production of these two hemp-lime blocks, however, tends not to be economically viable. The manufacture, curing and transport of the blocks from factory to site require considerable resources of space, time and energy. Mixing the hemp and lime binder with water on site and then trowelling or spraying the mixture into a shuttered timber frame construction or directly onto a brick surface has practical advantages.

Making building materials with straw and a binder is not new. For example, in the West Country, Devon UK, earth is mixed with straw and water to form a material called cob. The cob is then raised in layers to form walls with high thermal mass and low embodied energy. Again, using hemp, rice or wheat straw locks $\mathrm{CO}_{2}$ into the building material. A natural waste product is conveniently removed and a green building material is achieved when these straws are combined with a lime binder. Moreover, in November health issues arise in Egypt by the burning of rice straw, IRIN (2009). Incorporating rice straw in Egyptian building materials would therefore have two benefits, (a) reduction of the 'black cloud' health hazard, and (b) the sequestration of $\mathrm{CO}_{2}$.

The UK Building Regulations (2000) were revised in 2010. The 2010 edition of the thermal regulations were divided into (a), "Approved Document L1A: Conservation of Fuel and Power (New dwellings)", and (b), "Approved Document L1B: Conservation of Fuel and Power (Existing dwellings)", Building Regulations (2010). Similarly, two further documents concern buildings other than dwellings. The UK Building Regulations state that the limiting external wall thermal transmittance is $0.30 \mathrm{~W} / \mathrm{m}^{2} \mathrm{~K}$ for both new and existing dwellings. This value $\left(0.30 \mathrm{~W} / \mathrm{m}^{2} \mathrm{~K}\right)$ will be taken as the target thermal transmittance for this study. To illustrate the benefits of retrofitting insulation to the external surface of solid brick walls, Victorian dwellings in England will be used as the vehicle, since quantitative building details of Victorian terraced dwellings are available in the literature, Allen and Pinney (1990).

The term Victorian dwelling is used to describe UK houses built between 1840 and 1918, or sometimes called 'pre 1919'. Rivington (2004) discusses the various construction and materials found 
in the external walls of these houses. Any remedial strategy to reduce the heat loss through Victorian solid brick walls, walls without the benefit of a cavity, will need to recognise the importance of controlling the moisture content in the construction. The application of hemp-lime to the exterior has the advantage that the material is breathable, and it will therefore allow water vapour to pass through the material. The modified wall may get wet, but later it will dry.

\section{Aims}

This paper will present thermal data on solid brick walls modified by the addition of hemp-lime externally to improve the thermal performance of the walls. The discussion will compare the steadystate and transient thermal properties of some proposed brick wall constructions with added layers of insulating hemp-lime of various thicknesses.

Four aims can be identified.

1 To review the thermal properties of various examples of solid brick walls, and to highlight the need for additional insulation. The results of this section will also be used to validate the spread sheets constructed for this work to determine the thermal properties.

2 To report the steady-state and transient thermal properties of these walls when insulation has been added to the external surface.

3 To demonstrate how the thermal properties of these brick walls might be upgraded to meet the current UK thermal Building Regulations (2010); that is to achieve a U-value equal to or less than $0.30 \mathrm{~W} / \mathrm{m}^{2} \mathrm{~K}$.

$4 \quad$ To indicate potential energy saving and carbon dioxide reduction if solid single brick walls were insulated with external hemp-lime.

\section{Materials; walls and insulation}

A number of solid brick walls of various thicknesses with a variety of hemp-lime insulation added to the external surface of the walls will be considered. The addition of insulation to the exterior is considered to be the most effective and least intrusive method for decreasing the heat loss from these walls. However, the detailing will need careful control especially at the eaves, around windows, doors, ventilating bricks and at the party wall in semi-detached and terraced dwellings. At the eaves, a large roof overhang and suitable capping of the added insulation will needed. The problem of 
thermal bridging at the external surface of the party walls may need to be resolved. In the present paper only the thermal properties will be discussed.

The solid walls measured in brick thicknesses will be from 0.5 brick to 3.0 brick, or from $110 \mathrm{~mm}$ to $690 \mathrm{~mm}$ before the remedial hemp-lime layer is added. Hemp-lime can then be trowelled or sprayed into a suitable cavity, or directly onto the external surface. This material can also be placed in shuttering, adding layers carefully to avoid over compaction of the material, thereby reducing the thermal advantage gained by the inclusion of large quantities of still air. The mixture will then set and has the advantages of low embodied energy, high fire resistance, and resistant to fugal decay.

Following the timber frame technique, it is proposed that for some walls an external frame is constructed to allow temporary or permanent shuttering to be used. Simple plywood can be used, and where permanent external weather protection is necessary, tile hanging or tongued and grooved timber facing might be used to protect the insulation from wind driven rain in exposed areas. Problems of moisture penetration, structural stability and buildability would need to be considered carefully. Moreover, the problem of the hemp-lime possibly biodegrading if maintain in a wet condition would need to be addressed, especially at and just above ground level.

\section{Calculation of the time-dependent properties of walls}

The steady state thermal transmittance and transient thermal properties of the walls were determined following the method reviewed briefly in CIBSE (2006), pages 3-24 to 3-26 and in the Appendix 3.A6, pages 3-31 and 3-32. Microsoft Excel spread sheets were constructed to determine the thermal properties of the various walls, assuming the wall was exposed to sinusoidal temperature variations over a 24 hour cycle. The finite homogeneous solid layers of the walls were defined in terms of thickness, thermal conductivity, density and specific heat capacity. The conductivity and specific heat capacity values at the three densities of hemp-lime were given by lan Pritchett, Lime Technology Ltd., (private communication, 19 September 2011). For the transient thermal properties described in this work the mean specific heat capacity has been used and a sensitivity study will be given later.

Insert Table 1 
Table 1 reproduces the thermal properties of the various materials, the thermal resistances of the internal and external surfaces and that of the air cavity, taken from CIBSE (2006) page 3-47. The internal and external surface resistances were taken as 0.13 and $0.040 \mathrm{~m}^{2} \mathrm{~K} / \mathrm{W}$ respectively. The 50 $\mathrm{mm}$ air cavity thermal resistance was taken as $0.18 \mathrm{~m}^{2} \mathrm{~K} / \mathrm{W}$, again see CIBSE (2006) page 3-47. Table 1 shows brickwork data given for two cases, namely (1.5) protected and (1.6) exposed. An inner layer of brickwork separated by a continuous air space, or masonry protected by tile hanging or cladding is classified as protected. Alternatively, rendered or un-rendered masonry which is directly exposed to rain is classified as exposed. The insulation added externally to the brick walls is chosen from one of the three hemp-lime materials shown in Table 1, (1.7), (1.8) or (1.9). The ratios of the mass of hemp shiv to mass of lime based binder and the resulting material densities are given in Table 9. The new wall (1.7) and the roof hemp-lime (1.9) are recent improvements over the original old wall hemp-lime (1.8).

Insert Table 2

Table 2 reproduces thermal property data for a selection of walls taken from the current Design Guide, CIBSE (2006), Table 3.49. At Table 2, (2.1) an internally plastered 220mm brick wall has a Uvalue of $2.09 \mathrm{~W} / \mathrm{m}^{2} \mathrm{~K}$, an admittance about twice as large and a decrement lag time of 7.4 hours. This wall would loose about seven times too much heat in the steady state by modern standards, and would have shown a relatively rapid heat response to solar gain with a high decrement factor 0.42 with the lag time 7.4 hours. Walls (2.3), (2.4) and (2.5) show improving $U$-values with increasing insulation and a mixed picture regarding the decrement factors and lag times. The timber framed wall with $105 \mathrm{~mm}$ of brick has an acceptable U-value at $0.29 \mathrm{~W} / \mathrm{m}^{2} \mathrm{~K}$, but suffers with a high decrement factor and relatively short lag time. Here there is the potential for summertime overheating, when a high proportion, decrement factor 0.57 , of the incident solar radiation appears in the interior after a relatively short time lag time 6.5 hours.

The thermal properties shown in Table 2 in square brackets have been determined using the input thermal data given by CIBSE (2006) page 3-47, and the Microsoft Excel spread sheets constructed 
for this study. The good agreement between the CIBSE thermal properties and the values obtained using the spread sheets validates the software, and allows confident application of the spread sheets. The following results will illustrate how the thermal performance of brick walls of various thicknesses can be improved by adding different thicknesses of insulating hemp-lime externally.

\section{Results}

Following the aims stated earlier, the calculated results for the thermal properties of the existing brick walls, without added insulation, will be presented first. This will be followed by the presentation of the calculated thermal properties of the insulated walls. Finally, some walls for exposed weather areas will be discussed and walls able to meet the UK Building Regulations identified.

This section will include some discussion on how the insulation might be added to the exterior surface.

Insert Table 3

Table 3 shows a selection of brick walls all with the exposed classification and an internal $13 \mathrm{~mm}$ dense cement plaster layer, Table 3, (3.1) to (3.5), but some with an additional $25 \mathrm{~mm}$ external layer of cement render, Table 3, (3.6) to (3.11). These are assumed to be the two most likely states that the early brick walls might be found today, and the brickwork is assumed to range from $110 \mathrm{~mm}(0.5$ brick) to $680 \mathrm{~mm}$ ( 3 bricks). The most thermally unacceptable wall is the half brick with U-value 2.98 $\mathrm{W} / \mathrm{m}^{2} \mathrm{~K}$, Table 3, (3.1), $78 \%$ of the incident solar radiation arriving at the interior after only 3.6 hours. This construction would not provide adequate environmental filtering needed in a dwelling in temperate climates, with or without climate change. The thickest wall in this group, wall (3.5) at 693 $\mathrm{mm}$ still only has an $\mathrm{U}$-value of $0.93 \mathrm{~W} / \mathrm{m}^{2} \mathrm{~K}$, but at least this wall has a very low decrement factor at 0.01 and a long lag time of 23.5 hours. The group of walls with the additional external cement render show some thermal improvement, but again the wall $\mathrm{U}$-values are far from the modern requirement of $0.30 \mathrm{~W} / \mathrm{m}^{2} \mathrm{~K}$. At wall (3.11) with total thickness $718 \mathrm{~mm}, \mathrm{U}$-value $0.91 \mathrm{~W} / \mathrm{m}^{2} \mathrm{~K}$, the lag time is calculated at 0.31 hours. In the admittance calculations this lag time is determined and expressed as part of the daily twenty four hour cycle. For comparison with the other times in Table 3 , this 0.31 
hours has been added to 24 and shown in brackets as 24.31 hours. This convention will be adopted for the remaining tables and is used again in Table 5.

Insert Table 4

Table 4 shows a selection of solid walls all with the exposed classification for the $220 \mathrm{~mm}$ brickwork either with an internal $13 \mathrm{~mm}$ dense cement plaster layer, walls (4.1) to (4.4),or with $13 \mathrm{~mm}$ of lightweight plaster, walls (4.5) to (4.8), but all walls with $25 \mathrm{~mm}$ of lime and sand external render. The two groups of walls have an increasing thickness of new wall hemp-lime, Table 1, (1.7), sprayed directly onto the brickwork in thicknesses of $50 \mathrm{~mm}, 100 \mathrm{~mm}, 150 \mathrm{~mm}$ and $200 \mathrm{~mm}$ before the addition of the external finish of $25 \mathrm{~mm}$ lime and sand render. Here it is assumed that the original brickwork is sound, or if there was an external layer of cement render, or pebble-dash, that this would be in need of maintenance and therefore removed before the addition of the hemp-lime insulation. Comparing the two groups of results for the thermal performance of these walls given in Table 4 it is clear that the difference between dense and lightweight plasters is negligible. The dense plastered 50 $\mathrm{mm}$ insulated wall (4.1) has a U-value some $4 \%$ higher than the lightweight plastered wall (4.5), while the decrement factors differ by $7 \%$ and lag times are similar. The important conclusion to be drawn from the results shown in Table 4 is that for these $220 \mathrm{~mm}$ brick walls to meet the current Building Regulations and to have U-values less than $0.30 \mathrm{~W} / \mathrm{m}^{2} \mathrm{~K}$, then $150 \mathrm{~mm}$ of new wall hemp-lime is inadequate, while $200 \mathrm{~mm}$ of new wall hemp-lime would provide a margin for error. This is illustrated by comparing the U-values at (4.3) with (4.4) and at (4.7) with (4.8).

As mentioned above, when insulating these walls by spraying hemp-lime onto the brickwork, care would be needed to ensure the detailing at the eaves, around doors, windows and ventilating air bricks allowed effective treatment, and did not jeopardize these architectural features.

A possible solution to this problem would be to construct a timber frame, some sections temporary some permanent, around these architectural features allowing an air cavity between the brick and the insulation. Before the addition of the hemp-lime the exposed top sections of these cavities could be sealed with timber to prevent water penetration when rain water flows vertically down the wall. The next section presents some walls with air cavities formed using $50 \mathrm{~mm}$ studs and $12 \mathrm{~mm}$ plywood sheathing. 
Insert Table 5

Table 5 shows the thermal properties of twelve brick walls. There are three thickness of brickwork each with four different thickness of additional hemp-lime insulation. The brickwork thicknesses are $110 \mathrm{~mm},(5.1)$ to $(5.4), 220 \mathrm{~mm}(5.5)$ to (5.8) and $340 \mathrm{~mm}(5.9)$ to (5.12). Each wall has an air cavity of $50 \mathrm{~mm}, 12 \mathrm{~mm}$ of plywood sheathing then the layer of hemp-lime insulation followed by $25 \mathrm{~mm}$ of lime and sand render. The insulation is added in $50 \mathrm{~mm}, 100 \mathrm{~mm}, 150 \mathrm{~mm}$ or $200 \mathrm{~mm}$ thick layers. The thermal performance analysis is undertaken ignoring the parallel heat conduction through the timber studding. Temporary external plywood sheathing may be used as shuttering with studding of the appropriate thickness, and the internal timber may remain in place as it will be unaffected by the hemp-lime insulation. Table 5 shows that for the $110 \mathrm{~mm}$ brickwork only $200 \mathrm{~mm}$ of insulation would provide the necessary U-value to meet the Building Regulations, Table 5, (5.4), while for the 220 and $340 \mathrm{~mm}$ walls both $150 \mathrm{~mm}$ and $200 \mathrm{~mm}$ of insulation would achieve sufficiently low U-values, in the range 0.30 to $0.23 \mathrm{~W} / \mathrm{m}^{2} \mathrm{~K}$. Note that the lag time for the most massive wall, $340 \mathrm{~mm}$ brickwork with $200 \mathrm{~mm}$ of hemp-lime, Table 5, (5.12), is greater than twenty four hours at 27.8 hours, suggesting an extremely small contribution to the internal heat gain as the decrement factor is 0.01 . With the current interest in climate change, here is another advantage achieved by the addition of hemp-lime insulation; the insulation is helping to reduce the heat energy required in winter and helping to reduce the fabric solar gain in summer.

Insert Table 6

Table 6 shows the thermal properties of some $220 \mathrm{~mm}$ brick walls with an air cavity, plywood sheathing and the addition of various thicknesses of hemp-lime insulation. This table gives the properties of these walls when tile hanging is added to provide a rain screen for locations where the driving rain index is high. In the South West of England for example dwellings located on high moor land and coastal regions can be exposed to very heavy rain driven by high winds. While the hemplime insulation and the external lime and sand render are both breathable, they can take up water and then dry out. Nevertheless the conditions presented by a high driving rain index might cause wall 
damage over time. It would be sensible under these circumstances to protect the wall and shed the driving rain water using a tile hanging or similar screen. Table 6 shows the time-dependent thermal properties of air cavity hemp-lime insulated tile hung walls, again indicating that $200 \mathrm{~mm}$ of insulation would be required to satisfactorily meet the Building Regulations. The wall shown at Table 6, (6.4), has a U-value of $0.25 \mathrm{~W} / \mathrm{m}^{2} \mathrm{~K}$, while the small decrement factor 0.03 and long lag time of 20.17 hours show the thermal advantage possible in high summer.

\subsection{Sensitivity study}

There are two aspects of uncertainty in the results presented above that should be considered.

Firstly, there is a possible increase in thermal conductivity of the hemp-lime insulation due to moisture content and increase in density, due to the self-loading of the hemp-lime at installation. Secondly, the uncertainty in the thermal capacity creates uncertainty in the transient thermal properties.

\subsubsection{Uncertainty in thermal conductivity}

The hemp-lime thermal conductivity values given in Table 1 are for dry hemp-lime samples. Two factors cause the conductivity to increase, (a) increases in moisture content and (b) increases in density. Evrard (2008) has studied the influence of moisture content on hemp-lime samples and found a hemp-lime wall sample, with density $400 \mathrm{~kg} / \mathrm{m}^{3}$, had a conductivity of $0.11 \mathrm{~W} / \mathrm{mK}$ at relative humidity $0 \%$, but a value of $0.15 \mathrm{~W} / \mathrm{mK}$ when the $\mathrm{RH} \%$ reached $80 \%$. The hemp-lime thermal conductivities, shown in Table 1, demonstrate an increase with increasing density. In real walls the hemp-lime thermal conductivity might be greater than expected due to increases in moisture content and density. It will be assumed that a practical layer of new wall hemp-lime, called an installed layer, might have an increased thermal conductivity of $0.10 \mathrm{~W} / \mathrm{mK}$. Figure 1 shows that the U-value of a 220 $\mathrm{mm}$ solid brick wall varies with increasing thickness of added hemp-lime, and increases with increasing hemp-lime thermal conductivity. For this $220 \mathrm{~mm}$ solid brick wall with $200 \mathrm{~mm}$ of new wall hemp-lime to meet the target U-value the hemp-lime effective thermal conductivity should not be greater than about $0.07 \mathrm{~W} / \mathrm{mK}$, or below an increase of about $17 \%$. Figure 1 shows that if $300 \mathrm{~mm}$ of installed hemp-lime with effective conductivity $0.10 \mathrm{~W} / \mathrm{mK}$, (increased from $0.06 \mathrm{~W} / \mathrm{mK}$ due to density and moisture effects), was added to this $220 \mathrm{~mm}$ brick wall, the resulting insulated wall would still meet the target U-value of less that $0.30 \mathrm{~W} / \mathrm{m}^{2} \mathrm{~K}$. On the other hand, with $200 \mathrm{~mm}$ of installed hemp- 
lime insulation, with conductivity $0.10 \mathrm{~W} / \mathrm{mK}$, again as the result of increased density and moisture content, was added to this wall then the installed wall U-value would be $0.4 \mathrm{~W} / \mathrm{m}^{2} \mathrm{~K}$.

Insert Figure 1

Insert Table 7

\subsubsection{Uncertainty in specific heat capacity of hemp-lime}

Table 7 gives the thermal properties of the same $220 \mathrm{~mm}$ brick wall, but with different values of the hemp-lime thermal properties arising from the uncertainty in the thermal conductivity and specific heat capacity. Returning to Table 1 a range of specific heats were recorded for the three hemp-lime samples, and it is possible that the application of the hemp-lime by spraying or loading into shuttering may cause the density to be different from the values given for new wall hemp-lime, Table 1, (1.7). The insulation might be intended as low density 'roof' hemp-lime, Table 1, (1.9), but old wall hemplime, Table 1, (1.8) might result. Table 7 shows the results for walls of $220 \mathrm{~mm}$ brickwork with 150 $\mathrm{mm}$ of hemp-lime but with different insulation conductivities and specific heat capacities. The changes in conductivity will result in different U-values, while the ranges of specific heat capacity will be seen in the variation of the decrement factors and lag times. Comparing walls (7.1) and (7.2) the 7\% increase in specific heat capacity has given a $2 \%$ increase in the lag time, while comparing walls $(7.2)$ with (7.3), the new wall hemp-lime being replaced by new roof hemp-lime the reduction in conductivity of $16 \%$ has given a $12 \%$ reduction in the U-value. The two conclusions drawn from the results presented in Table 7 can be summarised as follows. Firstly, the lower density roof hemp-lime with its lower conductivity would be the insulation of choice as it leads to lower U-values. However, if this low density material was used then permanent shuttering would be an advantage to maintain the lower density, and care would be needed to stop the weight of subsequent layers compacting the earlier deposited hemp-lime, thereby increasing the density and increasing the conductivity. Secondly, the uncertainty in the specific heat capacities of the various hemp-lime materials does not lead to any significant changes in the overall picture of the transient thermal performance of these hemp-lime insulated brickwork walls. 


\section{Discussion}

Sustainability has three interwoven strands, Otto (2003). The three are: (a) the social aspects, about people, (b) the environmental aspects, about the planet, and (c), the economic aspects, about the profit. Clearly, the upgrading of solid brick walls found in Victorian dwellings will depend strongly on the people and the social aspects of the proposed modifications. The method of upgrading the thermal performance of heritage buildings will have to be socially acceptable, as well as efficient and economic.

Probert (2010) reports a small sample study of possible tenant participation in the sustainable issues focussed on the refurbishment of Victorian properties. The tenants of Victorian houses were very proud of their properties and expressed the view that water saving devices, draught proofing, loft insulation and double glazing were more important than possibly spoiling the external appearance of their homes in order to save energy. The survey suggested that people were more interested in comfort and security, in a new boiler and controls, while external insulation was only a little more attractive than internal insulation. The retrofitting of hemp-lime insulation to the exterior of solid brick walls has three important green or sustainable advantages, and two further social advantages. (1) The additional insulation produces a saving in the energy required to space heat the dwelling. (2) The sequestration of $\mathrm{CO}_{2}$ by growing hemp reduces the $\mathrm{CO}_{2}$ in the atmosphere. (3) The reduction in heating energy demand reduces the annual production of $\mathrm{CO}_{2}$. The sequestration of $\mathrm{CO}_{2}$ and its subsequent storage within the hemp-lime insulation is a single contribution to the reduction in $\mathrm{CO}_{2}$. However, the reduced energy demand provides an additional annual contribution to this reduction. The two further advantages of the addition of hemp-lime insulation are (4), the increase in comfort temperatures, and (5), the possible reduction in risk of occupant fuel poverty. These last two issues will not be discussed in this work. The first three sustainable advantages will now be discussed in detail.

\subsection{Energy saving}

Data produced by the National Building Agency and incorporated by Allen and Pinney (1990) shows the distribution of housing stock in the UK by house type, age and ownership. Table 1, Allen and Pinney (1990), shows that this stock has components; $3.4 \%$ pre-1919 semi-detached and $13.6 \%$ pre- 
1919 terraced houses. A second table, Allen and Pinney (1990), shows the distribution of house type with external wall construction. Here it is shown that 1.76 million terraced houses have solid brick walls with no cavity, or $68 \%$ of the pre- 1919 terrace houses. To this total the number of semi detached and end terraced properties 1.66 million must be added, giving a total of 3.4 million dwellings. The number of solid brick walled dwellings must decrease with time, as old condemned dwellings are demolished and modern dwellings are built, but there is a potential or possible energy saving if the remaining solid brick walls had an improved thermal performance. As existing housing accounts for over $25 \%$ of the UK $\mathrm{CO}_{2}$ emissions, Department of Communities and Local Government (DCLG) (2006), and with around 4 million Victorian properties, then if $20 \%$ of these dwellings were insulated a considerable reduction in energy demand would result and the $25 \%$ of $\mathrm{UK} \mathrm{CO}_{2}$ emissions from dwellings reduced to $17 \%$.

Insert Table 8

Table 8 shows the possible energy saving and $\mathrm{CO}_{2}$ sequestration by the remedial measure of adding $200 \mathrm{~mm}$ of hemp-lime insulation externally to the brick walls of period terrace dwellings. Models for the three possible Victorian terrace dwelling constructions are taken from Allen and Pinney (1990). The terraced houses have external solid brick walls $220 \mathrm{~mm}$ thick, are single glazed with loft insulation. By adding $200 \mathrm{~mm}$ of hemp-lime to the external walls the air to air thermal transmittance, or $\mathrm{U}$-value, is reduced from 2 to $0.26 \mathrm{~W} / \mathrm{m}^{2} \mathrm{~K}$. The reduction in heat loss is summarised in Table 8 , where the percentage reduction in design heating demand for hall to hall party wall, mid terrace and living room to living room party wall dwellings are $41 \%, 28 \%$ and $39 \%$ respectively. Assuming that space heating accounted for two-thirds of the total energy used in each dwelling then 27, 19 and $26 \%$, represents the potential financial savings on original fuel bills for the three types of dwelling.

\subsection{Sequestration of $\mathrm{CO}_{2}$ by hemp}

Table 8 also shows the potential for reducing carbon dioxide in the atmosphere by applying hemplime to these dwellings. Weight et al (2010) give the $\mathrm{CO}_{2}$ produced in manufacturing the lime binder as $0.427 \mathrm{kgCO}_{2}$ per $\mathrm{kg}$ of binder and the sequestration of $\mathrm{CO}_{2}$ by hemp as $-1.41 \mathrm{kgCO}_{2}$ per $\mathrm{kg}$ of hemp shiv. The net sequestration of carbon dioxide by the hemp-lime material will vary with density. 
Using the mixture proportions suggested by Lime Technology (2011), and reproduced in Table 9, the three types of hemp-lime studied in this paper, namely old wall with density $330 \mathrm{~kg} / \mathrm{m}^{3}$, new wall with density $275 \mathrm{~kg} / \mathrm{m}^{3}$ and roof with density $220 \mathrm{~kg} / \mathrm{m}^{3}$ have net sequestration rates of 61,85 and 108 $\mathrm{kgCO}_{2}$ per $\mathrm{kg}$ of added hemp-lime respectively.

Insert Table 9

Applying externally $200 \mathrm{~mm}$ of the new wall mixture to the three dwelling types, hall to hall party wall, mid terrace and living room to living room party wall, the carbon dioxide sequestrations are 385,212 and 352 tonne of carbon dioxide respectively. To place these sequestration rates in the context of the overall $\mathrm{CO}_{2}$ reduction proposed for the UK during the next forty years, up to the year 2050, the present dwelling $\mathrm{CO}_{2}$ production and the level proposed for 2050 are required. The $\mathrm{CO}_{2}$ emission associated with UK dwellings was $42 \mathrm{MtCO}_{2}$ per year in 2004, and it is proposed to reduce this to 17 MtCO2 by 2050, DCLG (2006). Given that there are 3.4 million Victorian properties, Allen and Pinney (1990), and taking the average sequestration rate of 316 tonne per dwelling, and if $20 \%$ of these properties were insulated with hemp-lime then the reduction in $\mathrm{CO}_{2}$ would be $215 \mathrm{MtCO}_{2}$. This would represent a significant contribution to the required reduction in $\mathrm{CO}_{2}$. If over the next 40 years the $\mathrm{CO}_{2}$ dwelling production is to be reduced from 40 to $17 \mathrm{MtCO}_{2}$ per year, then the figure of $215 \mathrm{MtCO}_{2}$ corresponds to seven years of mean annual production of $30 \mathrm{MtCO}_{2}$ per year. This represents the one-off reduction in $\mathrm{CO}_{2}$ by sequestration in the hemp-lime. There is a second reduction in $\mathrm{CO}_{2}$ since as the energy demand for each hemp-lime insulated dwelling is reduced, so the $\mathrm{CO}_{2}$ production associated with the energy conversion for space heating is also reduced.

\subsection{Reduction in $\mathrm{CO}_{2}$ due to reduced space heating energy demand}

It is difficult to extrapolate the individual house savings in both energy and $\mathrm{CO}_{2}$ production from space heating to give UK national figures. Firstly, there is the uncertainty in the total number of pre 1919 dwellings. Allen and Pinney (1990) gave the total number of pre 1919 terraced houses as 3.4 million. However, the Department of Communities and Local Government (2006) gives the number of pre 1919 dwellings as 4.4 million. Secondly, the energy used for space heating in dwellings is subjective and a function of remedial measures already undertaken, like the addition of double glazing, 
increased levels of loft insulation and draught proofing. However, an order of magnitude of this reduction in $\mathrm{CO}_{2}$ production can be obtained as follows.

Table 8 shows that for solid brick walls the mean reduction in heat loss as a result of the remedial addition of hemp-lime is $2470 \mathrm{~W}$ per dwelling. If the design temperature difference between the interior and exterior is $21 \mathrm{C}$ then this heat loss may be expressed as a heat loss rate per degree of $118 \mathrm{~W} / \mathrm{K}$. Taking the dwellings to be in the London area where heating is required for 2663 degreedays (K.days) (Heathrow (1982-2002), reference temperature 18C, CIBSE (2006), Table 2.23, page $2-14)$, then this saving is equivalent to $7517 \mathrm{kWh}$ per year per dwelling. Assuming gas fired central heating, where $1 \mathrm{kWh}$ gas heating produces $0.184 \mathrm{~kg} \mathrm{CO}_{2}$, Carbon Trust (2010), then the insulated dwelling provides a $\mathrm{CO}_{2}$ saving of $1380 \mathrm{kgCO}_{2}$ per year per dwelling. Following the sequestration example, section 6.2 above, then assuming that $20 \%$ of the 3.4 million dwellings achieved this $\mathrm{CO}_{2}$ reduction the saving for the $\mathrm{UK}$ is $0.94 \mathrm{MtCO}_{2}$ per year. This represents a $5 \%$ contribution to the proposed saving of $17 \mathrm{MtCO}_{2}$ per year sought by 2050 . Moreover, if electricity is used for space heating in these dwellings, instead of gas, then the potential saving is about $15 \%$, since $1 \mathrm{kWh}$ of electricity produces $0.544 \mathrm{kgCO}_{2}$, Carbon Trust (2010).

\section{Conclusions}

Addressing the four aims identified earlier, in Section 2, the following conclusions can be drawn. 1 The thermal properties of some examples of Victorian solid brick walls have been determined. For example, a $110 \mathrm{~mm}$ ( 0.5 brick) thick wall with $13 \mathrm{~mm}$ of dense plaster has U-value (U) $3.0 \mathrm{~W} / \mathrm{m}^{2} \mathrm{~K}$, lag time (L) $3.6 \mathrm{hr}$ and decrement factor (D) 0.78 , while a $680 \mathrm{~mm}$ (3.0 brick) thick wall has $\mathrm{U}, \mathrm{L}, \mathrm{D} ; 0.9 \mathrm{~W} / \mathrm{m}^{2} \mathrm{~K}, 23.5 \mathrm{hr}$ and 0.01 respectively. Clearly, these walls require additional insulation to meet current regulations with $\mathrm{U}$-value of $0.30 \mathrm{~W} / \mathrm{m}^{2} \mathrm{~K}$.

2 The thermal properties of these walls when hemp-lime insulation has been added to the exterior surface are given. For example, the thermal properties of a $220 \mathrm{~mm}$ (1.0 brick) thick wall with $13 \mathrm{~mm}$ of dense plaster with additional layers of hemp-lime 50, 100 and $200 \mathrm{~mm}$ are reported. This un-insulated wall has $U, L, D$ of $2.1 \mathrm{~W} / \mathrm{m}^{2} \mathrm{~K}, 7.6 \mathrm{hr}$, and 0.41 respectively. With the addition of 50,100 and $200 \mathrm{~mm}$ of hemp-lime the $\mathrm{U}, \mathrm{L}$ D values are $\left(0.75 \mathrm{~W} / \mathrm{m}^{2} \mathrm{~K}, 11.2 \mathrm{hr}, 0.14\right) ;\left(0.46, \mathrm{~W} / \mathrm{m}^{2} \mathrm{~K}, 14 \mathrm{hr}\right.$, $0.1)$ and $\left(0.26 \mathrm{~W} / \mathrm{m}^{2} \mathrm{~K}, 20.5 \mathrm{hr}, 0.03\right)$ respectively. Here the addition of $200 \mathrm{~mm}$ of hemp-lime would meet the UK thermal regulations. When a $50 \mathrm{~mm}$ air cavity is introduced between the brick and the 
insulation for walls 220 and $340 \mathrm{~mm}$ thick, then $150 \mathrm{~mm}$ of hemp-lime is sufficient to meet the UK thermal regulations. A similar wall with $110 \mathrm{~mm}$ brick would require $200 \mathrm{~mm}$ to ensure that the U-value was less than $0.30 \mathrm{~W} / \mathrm{m}^{2} \mathrm{~K}$.

3 This work demonstrates that the thermal properties of these brick walls might be upgraded to meet the current United Kingdom Building Regulations by the addition of suitable external layers of hemp-lime to achieve wall U-values less than $0.30 \mathrm{~W} / \mathrm{m}^{2} \mathrm{~K}$.

4 The possible energy saving and $\mathrm{CO}_{2}$ reduction if single brick walls were insulated with external hemp-lime is described and discussed. For Victorian terraced dwellings with $220 \mathrm{~mm}$ solid brick walls the addition of $200 \mathrm{~mm}$ of hemp-lime reduces the $\mathrm{U}$-value from 2.0 to $0.26 \mathrm{~W} / \mathrm{m}^{2} \mathrm{~K}$. For hall to hall party wall, mid terrace and living room to living room party wall dwellings the percentage reductions in design heating demand are $41 \%, 28 \%$ and $39 \%$ respectively. The potential sequestrated $\mathrm{CO}_{2}$ in these three types of dwellings with hemp-lime insulation to meet the UK thermal regulations are 385,212 and $352 \mathrm{tCO}_{2}$ respectively.

This work demonstrates that there are possible energy and carbon dioxide savings when externally insulating these Victorian dwellings with hemp-lime. This conclusion would apply to all similar brick walled dwellings. However, the issues of acceptance in terms of appearance, buildability and cost have still to be resolved.

\section{Acknowledgement}

The authors wish to thank lan Pritchett, Lime Technology Ltd., Didcot, for his kind help providing the hemp-lime thermal data.

\section{References}

Allen E A and Pinney A A (1990). "Standard dwellings for modelling: details of dimensions, construction and occupancy schedules". Building Environmental Performance Analysis Club (BEPAC), Technical note 90/2. Building Research Establishment, Watford, UK. Bevan R and Woolley T (2008). "Hemp Lime Construction”. IHS BRE Press, Bracknell. 
Building Regulations (2010). "Conservation of Fuel and Power. Approved document L1 Conservation of fuel and power in dwellings". Effective from October 2010. 2010 Edition, DTLR. Published by NBS part of RIBA Enterprises Ltd., London.

http://www.safety.odem.gov.uk/bregs/brpub/ad/ad-11/index01.htm, (accessed 20 October 2011).

"Approved Document L1A; New dwellings":

http://www.planningportal.gov.uk/uploads/br/BR_PDF_ADL1A_2010.pdf (accessed 19 October 2011). "Approved Document L1B; Existing dwellings":

http://www.planningportal.gov.uk/uploads/br/BR_PDF_ADL1B_2010.pdf (accessed 19 October 2011). Building Regulations (2000). "Conservation of Fuel and Power. Approved document L1 Conservation of fuel and power in dwellings". Effective from April 1, 2002. 2002 Edition, DTLR, The Stationery Office, London http://www.safety.odem.gov.uk/bregs/brpub/ad/ad-11/index01.htm, (accessed 14 November 2002).

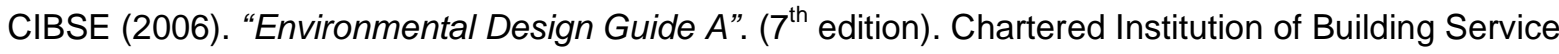
Engineers, London. Page Bros. Ltd., Norwich, UK.

Department of Communities and Local Government (DCLG) (2006). "Review of sustainability of existing buildings". CLG, UK.

www.communities.gov.uk/documents/planningandbuilding/pdf/154500.pdf, (accessed 19 May 2010). Evrard A (2008). "Transient hygrothermal behaviour of lime-hemp materials". PhD Thesis in Applied Sciences, Universite Catholique De Louvain.

HSB (2011). Issue 3: "English Housing Survey Bulletin; A newsletter for users of the English Housing Survey". Headline Report 2009-10 [1] HSB 2008. Housing Surveys Bulletin, Issue 3 - November 2008.

http://www.communities.gov.uk/publications/housing/hsbulletin03 (accessed 20 October 2011). HSB (2008). Housing Surveys Bulletin, Issue 3 - November 2008.

http://www.communities.gov.uk/publications/housing/hsbulletin03 (accessed 20 October 2011). IRIN (2009). "EGYPT: Black cloud with a silver lining”. CAIRO, 9 November 2009 (IRIN) http://ww.irinnews.org/Report.aspx?Reportld=86933, (accessed 14 October 2011). Lime Technology (2009a). "Hemcrete Thermal Block: Information sheet, HTB0509.v2" http://www.limetechnology.co.uk, accessed (15 November 2009). Lime Technology (2009b). "Hemcrete Structural Block: Information sheet, HSB0509.v2" 
http://www.limetechnology.co.uk, accessed (15 November 2009).

Lime Technology (2011). "Tradical Hemcrete U-values: Product Datasheet, H0111.v3"

http://www.limetechnology.co.uk, (accessed 16 October 2011).

Otto, B K (2003) “About: sustainability”, Design Council, UK.

http/www.designcouncil.org.uk/webdav/servlet/XRM?Page/@id=6004\&Session/@id=D_wK2jr8zM7zu

mIQsB2NDz\&Section/@id=1317, (accessed 12 October 2010).

Pett J (2001). "Affordable warmth for 'hard to heat' homes: Finding a way forward?" Discussion paper

DP 06. Association for the Conservation of Energy, London.

http://www.ukace.org/publications/ACE\%20Discussion\%20Paper\%20(2001-11)\%20-

\%20Affordable\%20Warmth\%20for\%20'Hard\%20to\%20Heat'\%20Homes (accessed 20 October 2011).

Probert A (2010). "Tenant participation in the sustainable refurbishment of Victorian properties". The Environmentalist, IEMA 15 March issue 94, pp 17-22.

Rivington (2004). "Rivington's Series of Notes on Building Construction”, (first published 1875).

Revised and enlarged in 1904, Longmans, Green and Co. London. Reprinted by Donhead Publishing Ltd., Shaftesbury, Dorset, UK, 2004.

Weight D, Langdon D and Norton A (2010). "Climate change and the role of biomass based building materials". Davis Langdon Global construction consultants, 201006 22. Report on Renewable carbon for National Non-Food Crops Centre (NNFCC), York, UK. 